\title{
8-2018
}

\section{Pregnant Behind Bars: Meeting the Nutrition Needs of Incarcerated Pregnant Women}

\author{
Catherine A. Forestell \\ William \& Mary, caforestell@wm.edu \\ Danielle H. Dallaire \\ William \& Mary, dhdall@wm.edu
}

Follow this and additional works at: https://scholarworks.wm.edu/asbookchapters

Part of the Dietetics and Clinical Nutrition Commons, and the Psychology Commons

\section{Recommended Citation}

Forestell, C. A., \& Dallaire, D. H. (2018). Pregnant Behind Bars: Meeting the Nutrition Needs of Incarcerated Pregnant Women. Lammi-Keefe, Carol J., Couch, Sarah C., Kirwan, John P. (Ed.), Handbook of Nutrition and Pregnancy (pp. 295-307). Humana Press, Cham. https://scholarworks.wm.edu/asbookchapters/112

This Book Chapter is brought to you for free and open access by the Arts and Sciences at W\&M ScholarWorks. It has been accepted for inclusion in Arts \& Sciences Book Chapters by an authorized administrator of W\&M ScholarWorks. For more information, please contact scholarworks@wm.edu. 


\section{Pregnant Behind Bars: Meeting the Nutrition Needs of Incarcerated Pregnant Women}

Catherine A. Forestell $\mathrm{PhD}{ }^{1 \square}$

Email caforestell@wm.edu

Danielle H. Dallaire $\mathrm{PhD}^{1}$

${ }^{1}$ Department of Psychological Sciences, The College of William \& Mary, Williamsburg, VA, USA

\section{Abstract}

The abstract is published online only. If you did not include a short abstract for the online version when you submitted the manuscript, the first paragraph or the first 10 lines of the chapter will be displayed here. If possible, please provide us with an informative abstract.

The number of women involved in the criminal justice system has increased dramatically over the past 20 years. Due to their marginalized background, incarcerated women have a complex set of health-related needs. This is especially true of those who are pregnant, a particularly vulnerable, high-risk group. Although guidelines have been developed that recommend pregnancy screening, provision of dietary supplements, regular nutritious meals, and nutritional counseling for incarcerated pregnant women, jail policies and health care protocols often fail to heed these recommendations. In this chapter, we discuss the nutritional needs of pregnant incarcerated women as well as breastfeeding in the context of the criminal justice system and consider some of the challenges in developing programming and policies to address these health-related needs. We also present findings from the William \& Mary Healthy Beginnings Project, a nutrition intervention program developed for pregnant incarcerated women in Southeastern Virginia. Assessment of this program suggests that through the development of protocols and polices that consider the health-related needs of pregnant women, correctional facilities could play a pivotal role in helping incarcerated women develop healthier habits to better care for themselves and their newborns.

\section{Keywords}

Incarceration

Nutrition knowledge

Breastfeeding

High-risk pregnancy

Jail

Prison

\section{Key Points}

- Due to their marginalized background, incarcerated pregnant women have a complex set of health-related needs.

- Medical guidelines recommend screening for pregnancy upon entry, routine prenatal care, provision of dietary supplements, and regular nutritious meals during incarceration.

- Jail protocols often fail to address these recommendations and as a result pregnant women's health-related needs are often underserved. 
- Evidence from the William \& Mary Healthy Beginnings Program suggests that incarceration could be an ideal opportunity to provide pregnant women with health-related skills to better care for themselves and their newborns.

\section{Introduction}

Over the past 20 years, the population of female inmates has almost doubled in the United States, rising from 51,300 in 1996 to 93,300 in 2011 [1]. Despite this large increase, incarcerated women make up less than 10\% of the overall imprisoned population [2]. As a result, jail policies, health-care protocols, and interventions, which continue to focus primarily on men [3], fail to consider the gender-specific needs of the growing female population [4]. This lack of attention to the complex health-related needs of women often results in the neglect of their human rights and in social injustices $[5,6]$.

Women in the correctional system are typically of childbearing age (between 18 and 44 years old), [7] and approximately $6-10 \%$ of incarcerated women are pregnant [8]. This represents a significant challenge for the criminal justice system because the pre- and postnatal needs of this high-risk group of women and their babies are extensive. In the current chapter we will foeus on the nutritional needs of incarcerated pregnant women. We will first describe the characteristics of incarcerated women and consider how involvement with the criminal justice system impacts their nutritional status during pregnancy. Next, we will discuss postpartum needs of incarcerated women and their newborn babies, with a special focus on breastfeeding in the context of incarceration. Finally, we will describe the William \& Mary Healthy Beginnings Project; a nutrition intervention implemented with pregnant incarcerated women throughout Southeastern Virginia, and report on how this program affects women's nutritional knowledge and their birth outcomes. Our discussion of correctional facilities will include jails, which typically incarcerate people for relatively short periods of time; often as little as a couple of hours and generally not longer than 1 year, as well as prisons, which incarcerate people for longer periods of time for more serious offenses [9].

\section{A Profile of Women in the Criminal Justice System}

Incarcerated women represent a population marginalized by race, class, and gender [10]. These women are disproportionally from ethnic or racial minorities, and theymany lack educational and vocational training [11]. They tend to struggle with poverty, trauma, such as physical and sexual abuse, mental illness, such as depression and post-traumatic stress disorder, and drug addiction $[12,13]$. Research indicates that for many women, these psychological and social issues motivate their criminal behavior [14,15]. This is demonstrated by the types of crimes they commit, which commonly involve drug or property offenses rather than violent crimes [11].

Their extensive history of substance abuse is often linked with commercial sex work and other risky sexual behaviors [16], yet, in a recent study, close to $75 \%$ of sexually active incarcerated women reported inconsistent or no birth control use [17]. As a result, these women are at an elevated risk for reproductive health problems, such as HIV and other sexually transmitted diseases, in addition to unintended pregnancies. Because incarcerated women are more likely than those from the general population to experience high-risk pregnancies [18] they require considerable support. Despite this need, they are unlikely to seek prenatal care while in the community. Given that pregnancy is a significant life-changing event for many women, correctional facilities have the unique opportunity to provide services and support to a group of high-risk women at an important turning point in their lives [17]. Yet, according to a 2006 report by the Department of Justice, less than half of pregnant women in the United States receive a medical examination upon intake at a correctional facility or appropriate care during incarceration [19].

Indeed, some research has shown that women who are incarcerated in jails for longer periods of time appear to benefit from better prenatal care, improved nutrition, and a structured environment with more favorable perinatal outcomes [20, 21]. However, these findings have not been consistently supported [18]. It is likely that the association between length of jail stays and birth outcomes is moderated by other variables. Bell et al. [18] found 
that the length of incarceration was positively associated with birth weight only in white women incarcerated during their first trimester. Furthermore,Because women in jails, as opposed to prisons, are more likely to be incarcerated for relatively short periods of time, and likely benefit fromthey are more reliant on services and resources that can be utilized in their communities.

\section{The Nutritional Needs of Incarcerated Pregnant Women}

Although some may think that incarcerated pregnant women should receive care comparable to women in the community, there are additional institutional considerations that make caring for this group of women more complicated. Specific conditions posed by the jail environment as well as personal health issues such as drug addiction, increased risk of infectious diseases, and mental health problems must also be considered with this high-risk population. With these considerations in mind, various medical groups, including the National Commission on Correctional Health Care (NCCHC) and the American College of Obstetricians and Gynecologists (ACOG), have developed guidelines for providing care to pregnant incarcerated women. These guidelines include a range of recommendations, such as screening for substance abuse, mental health, and pregnancy upon entry to the facility; routine prenatal care from qualified health professionals; appropriate treatment for substance abuse; and provision of dietary supplements and regular nutritious meals [8,22].

Meeting the dietary needs of pregnant women is particularly important in corrections facilities because many come from food-insecure environments and will likely be returning to these environments after their release. Although the $\mathrm{NCCHC}$ recommends dietary supplements of folate $(600 \mathrm{mcg})$, their dietary guidelines are otherwise vague [22]. While adequate folic acid intake protects the fetus from neural tube defects, low birth weight, and prematurity [23], iron is also recommended (27 $\mathrm{mg} /$ day) to protect against a range of negative birth outcomes, such as risk of preterm delivery and low birthweight [24]. Yet, despite their importance, the recommended levels of folic acid and iron are often not met in meals served in correctional settings [25], and many facilities fail to provide prenatal vitamins [26], which serve as an important dietary supplement of folic acid and iron.

In addition to folic acid and iron, other nutrients are needed to promote positive pregnancy outcomes that are not addressed in the NCCHC guidelines. For example, the degree to which our bodies absorb iron is dependent on vitamin C intake; as a result, adequate consumption of fruits and vegetables, which are high in vitamin $\mathrm{C}$, is vital. Moreover, adequate levels of omega3 fatty acids are especially important for this high-risk population because they are associated with longer pregnancies, increased weight gain, and brain development in the fetus $[27,28]$, as well as decreased postpartum depression for the mother [29]. Because our bodies cannot produce these fatty acids, we get them from dietary sources such as fatty fish like salmon and omega-3 fortified milk and yogurt. These foods additionally provide vitamin $\mathrm{D}$, which aids in the absorption of calcium, an important nutrient for the development of bones and teeth and proper functioning of the circulatory, muscular, and nervous systems. More recent research suggests that vitamin D may affect susceptibility to chronic diseases soon after birth as well as later in life [30].

Because vitamin D is primarily produced endogenously in the skin with exposure to sunlight, incarcerated women are at high risk for deficiency given their limited sun exposure. According to the Food and Nutrition Board at the Institute of Medicine of the National Academies of Science, adequate intake of vitamin D during pregnancy and lactation is 600 international units (IU) per day [31]. However, it has recently been suggested that higher daily intake — up to 4000 IU per day [32] — may be optimal for maintaining maternal vitamin D sufficiency during pregnancy.

From a cultural perspective, food has important symbolic power for pregnant women because it provides the nourishment needed not only for their own bodies, but it also serves as a lifeline for the developing fetus. For most pregnant women, food choices are driven not only by internal factors such as cravings and aversions, but they are also influenced by the cultural food practices and beliefs that have been created through past experiences and are grounded in their race, class, and culture (see [33] for a review). While incarcerated, inmates lack the freedom to make food choices that reflect their preferences and cultural backgrounds. This can serve as 
a source of anxiety and frustration [34]. For some, a creative and social outlet that counters the constraints of jail food involves the invention of alternative meals called "spreads" or "swoles." These concoctions are most often built around a single ingredient, such as instant ramen noodles that can be purchased through the jail commissary (see [35] for an overview of this practice). Beginning with this noodle base, inmates create variations from foods provided in their meals and the commissary to approximate their favorite foods, which often have distinctive flavorings and textures. In this manner, pregnant women may assume some responsibility for their own intake, however the addition of swoles to the diet, though they may add calories, does not necessarily improve nutrition [5].

While overweight

Obesity

and obesity during pregnancy heightens the risk of conditions like pre-eclampsia, gestational diabetes, and postpartum hemorrhage, undernutrition negatively impacts embryonic and fetal growth and development.

Moreover, recent research shows that the mother's eating behavior during the 3 months prior to conception and during prenatal development can have long-lasting effects on her children, increasing the incidence of disease states, such as obesity and diabetes, over the course of their lives. Epigenetic changes that occur as a function of a poor diet serve to "tune" the phenotype, causing the child to become predisposed to metabolic disorders later in life, such as obesity or cardiovascular disease [36]. Perhaps even more concerning, these predispositions can be passed down to subsequent generations through the process of transgenerational inheritance [37]. In this manner, certain biological predispositions are passed from generation to generation not through the promotion of genetic mutations in DNA sequence, but rather through altered gene expression. Thus, a woman's diet, whether it lacks essential nutrients that ultimately produce malnourishment or it provides excessive calories through the overconsumption of energy-dense foods, not only negatively impacts her own health, but also that of her children and potentially her grandchildren. Given the far-reaching effects of poor nutrition during prenatal development, it is important to develop effective interventions that help to mitigate such risk in pregnant incarcerated women.

\section{The Challenges of Meeting Nutritional Needs of Incarcerated Pregnant Women}

Though the health, nutrition, and well-being of pregnant inmates should be a priority for correctional facilities, it is costly. Many state corrections departments have a registered dietitian nutritionist on staff who oversees the nutritional value of meals served to inmates, however currently, there are no federal regulations that mandate nutritional standards of correctional facilities [25]. Moreover, because financing of correctional facilities depends on legislative appropriations that compete with other important issues, provision of sufficient nutrition for inmates, and especially pregnant women, is often not a fiscal priority. As a result of poor funding and oversight, incarcerated pregnant women's dietary needs are often underserved, with many jails failing to provide heathier food options to these women [38].

Correctional facilities often attempt to offset the cost of meals by providing foods that are heavily processed, high in sodium, and contain high levels of texturized vegetable protein and soy, which can be unpalatable and difficult to digest. In many facilities deli meats, such as bologna and hot dogs, are a staple, which carry the risk of contamination by Listeria, a bacteria that can cause fetal complications [39]. On average, the cost of each meal at correctional facilities ranges from $\$ 3$ to $\$ 4$ per inmate [25]. Some facilities provide pregnant inmates with an additional daily snack, however access to fresh fruits and vegetables, unprocessed meat and fish, whole grains, and milk can be limited, and the food provided does not necessarily meet the nutritional or caloric requirements for pregnant women $[25,40]$.

In addition to the lack of quality of meals, their timing, presentation, preparation, and the size of portions are usually tightly controlled by the facility. For women who are pregnant, this aspect of institutional control has a range of health-related consequences. Because many women suffer from nausea or acid reflux during pregnancy, they may prefer to eat multiple small meals a day to aid in digestion and reduce nausea. This is difficult to achieve in most jail settings, where the timing and portion size of meals is inflexible. In most cases, if a pregnant 
woman chooses not to eat during a scheduled meal, she will likely not have the opportunity to eat until the next meal is served.

In view of the challenges that pregnant women face in correctional settings, Shlafer et al. [41] have suggested best practices for addressing the dietary needs of incarcerated pregnant women. In addition to suggesting approaches to increase incarcerated pregnant women's access to nutrients, calories, and water, they advocate for providing inmates with education on proper nutrition. Because many pregnant women who are involved in the criminal justice system have relatively low levels of health literacy, they are often unaware of how their dietary habits ean-impact their developing fetus, and they engage in poor nutritional habits that can lead to serious complications before and after their pregnancies [42]. Incarceration could be an ideal opportunity to provide educational programming that focuses on a variety of health-related topics, including nutrition. Previous research has shown that nutrition education programs not only improve women's nutritional knowledge [43], but they can also improve birth outcomes in low-income women [44]. Although educational programs could be an effective means for improving birth outcomes in incarcerated women, they are limited in most jail facilities.

\section{Breastfeeding in the Context of Incarceration}

The World Health Organization (WHO) and American Academy of Pediatrics (AAP) recommend that infants should be exclusively breastfed from birth to six months of age, barring contraindications [45, 46]. It is well documented that breastfeeding has a direct beneficial effect on infants by promoting growth and normal development, and providing immunological protection against various infantile diseases and infections. Because the flavor of the mother's milk reflects the flavors of the foods she eats, breastfeeding also provides one of the earliest opportunities for children to learn to appreciate the flavors of their culture [47]. In support of this early learning, research shows that infants who are breastfed are less likely to become picky eaters [48, 49]. But lactation is far more than merely a biological process that helps to prevent disease and to develop a healthful diet; it represents an important aspect of mothering that involves the formation of an emotional connection or bond between a mother and her child. That this bond benefits both mother and child is supported by research that demonstrates that mothers who breastfeed are more sensitive in responding to the cues of their infants [50, 51]. Of special note for incarcerated women, who tend to experience profound sadness and clinical depression $[52,53]$, breastfeeding has been shown to decrease mothers' negative affectivity $[50,54,55]$.

Recent research from our laboratory suggests that women who are incarcerated for longer periods of time and those with poorer diets are less likely to initiate breastfeeding [56]. These findings may be connected to a number of factors, such as the lack of prenatal education that women receive while they are incarcerated. The longer women are incarcerated during pregnancy, the less accessibility they have to early prenatal breastfeeding programs. Studies show that early breastfeeding support $[57,58]$ that addresses a range of topics including the benefits of breastfeeding, principles of lactation, common problems and their solutions, and skills training increase breastfeeding initiation [59].

To be sure, the practice of breastfeeding is surrounded by a great deal of folklore, especially regarding the dietary practices of the mother. For example, in a qualitative study conducted by Hannon et al. [60] adolescent minority mothers reported beliefs that certain foods, such as chocolate, orange juice, and corn, should be avoided while breastfeeding. Although few of these traditional beliefs are supported by scientific evidence, they continue to be communicated to new mothers. In order to counteract these breastfeeding myths, additional information about how maternal dietary habits affect the quantity and quality of milk may also be helpful, especially for those with poor diets. While it is possible that women with poor dietary behaviors may be less likely to initiate breastfeeding because they are less interested in engaging in healthful behaviors, they may also mistakenly believe their poor diet prevents them from producing nutritious breastmilk for their babies [58, 61]. Mothers may be more inclined to breastfeed if they believe that the quality of their breastmilk does not depend on eating a highly nutritious diet. Rather, the importance of a healthy diet for the mothers' own benefit should be emphasized through educational programs [62]. 
In order to increase breastfeeding initiation among incarcerated mothers, changes in protocols are necessary in most US jails. Currently, many states do not have laws or statutes that prevent jails from denying inmates lactation accommodations. Women who return to jail after the birth of their child are generally not permitted to pump their breastmilk for their newborn, and they are unable to have contact visitations that would make breastfeeding possible. Despite this inability, there is evidence to suggest that breastfeeding is valued by some incarcerated pregnant women [61]. Given the important benefits that breastfeeding confers to both the mother and child, both federal and state legislatures should consider enacting laws that promote breastfeeding in correctional facilities. Not only should jail protocols facilitate breastfeeding for incarcerated women with infants, but they should also provide comprehensive prenatal education to increase breastfeeding initiation amongst these women.

In many other countries, such as Canada, the United Kingdom, Germany, Bolivia, and Kenya, incarcerated women are able to keep their infants through weaning and, in some cases, longer [63]. Although several states, such as New York, Nebraska, South Dakota, Washington, and California [63] have prison nurseries, similar facilities are not available in most jails. This need is addressed through residential mother-child programs for women who have shorter sentences in other countries. In the USA, these community-based programs are not widespread, and those that do exist are often limited to women who suffer from drug addictions.

\section{The William \& Mary Healthy Beginnings Project}

In an attempt to address the needs of pregnant incarcerated women in Southeastern Virginia, our group developed the William \& Mary Healthy Beginnings Project. The goal of this program is to provide resources and nutrition information in a manner that is not intimidating and is personalized for the needs of the participants. In addition to providing jails with pregnancy tests to identify pregnant women upon entering each facility, and prenatal vitamins for all women for the duration of their pregnancy, nutritional counseling is delivered. Our primary participants include women who range in age from 19 to 41 years of age. Almost all (90\%) of these women are single, approximately half (55\%) are African American, half (49\%) have not completed high school, and about a quarter (24\%) are first-time mothers. Prior to pregnancy, $83 \%$ reported smoking cigarettes regularly, $50 \%$ reported using illegal drugs, and 23\% report being homeless. Amongst women who have previous children, $17 \%$ report having had a premature baby and $14 \%$ report having a low-birth-weight baby. To put this into context, approximately $11 \%$ of babies are born preterm in Virginia and there is a state-wide goal to reduce this rate to $8 \%$.

Nutrition counseling sessions begin with motivational interviewing techniques to discuss participants' pregnancy-related goals. This is followed by an activity in which each participant fills an empty plate with images of various foods that they would be most likely to eat if the foods were available. Participants select a main course, a starch, a vegetable, a dessert, and a drink from a variety of pictures of foods that range in caloric content and healthfulness. This activity provides an opportunity for the team member to discuss the nutritional benefits of the participants' selections and acts as a segue for discussing guidelines for healthy eating using the USDA ChooseMyPlate.gov handout. Because the recommendations on this handout are for adults who are not pregnant, team members also discuss pregnancy-related issues such as the dangers associated with consuming deli meats and frequent consumption of certain types of fish during pregnancy. The team member also reviews nutritional content of various foods such as whole versus skim milk, how to read food nutrition fact labels, and the contents and benefits of vitamins and minerals in foods and prenatal vitamins. Throughout the session, the team member endeavors to provide information that is relevant and personalized for the participant. For example, if a pregnant women is in a jail that provides her with a "snack bag," the team member will discuss the contents of the snack and the added nutrition provided. In cases where these snacks consist of a cold bologna sandwich (or similar deli meat), we inform the women that they can request a snack that has a peanut butter sandwich to decrease the chance of contracting Listeriosis. There is also an opportunity for the participant to report and discuss any pregnancy-related ailments she may be experiencing (e.g., nausea, heart burn). In addition, participants' pre-pregnancy body mass index (BMI) is calculated, and based on this, the research team member discusses participants' suggested weight gains following the recommendations [64]. On average, nutritional counseling sessions last between 45 and $75 \mathrm{~min}$. In subsequent visits, team members follow up with 
participants to provide them with additional support, information, or referrals for other services, if requested. For example, the team member will discuss issues that are personally relevant to the women, such as breastfeeding or addiction, assist women with completing paperwork required to receive resources, such as Medicaid, WIC, or a free car seat, or provide referrals to programs, such as those that offer residential drug rehabilitation.

Close to one-third of the participants in this program discovered they were pregnant upon entering the jail facility. This was a direct result of the pregnancy tests provided by the William \& Mary Healthy Beginnings Project. Because these women were identified early, they were able to receive prenatal vitamins and timely prenatal care, as well as nutrition counseling and additional support to help them plan for their pregnancy. Moreover, our results show participants' nutrition and pregnancy-related knowledge increased from pre- to postcounseling, and this increase in knowledge was associated with positive birth outcomes [65].

Our hope is that incarcerated pregnant women will start to feel empowered to make better choices about the foods they consume. Although, as discussed above, the correctional environment poses certain immediate challenges to accomplishing this goal, there are some opportunities to help pregnant women make healthier nutrition decisions while incarcerated. For example, discussing the value of food choices that they make when purchasing commissary items and encouraging them to eat the vegetables provided to them in their meals may help to improve their diet while in jail. There are also straightforward changes that jails could make to aid women's food choices. For example, providing a list of commissary items that may be healthy options for pregnant women or labeling such foods would help increase self-efficacy and promote adherence to nutrition recommendations. In addition, correctional facilities should include a list of items that may be unsafe for pregnant women (e.g., uncooked deli meat) and foods that should be consumed in moderation [41]. Once women are released, their improved nutrition knowledge may enhance the nutritional quality of the foods they purchase for themselves and for their families with the resources they have available. It is also our hope that through discussions about the advantages of breastfeeding during program meetings, women who deliver after their release will be more likely to initiate this important feeding regimen with their newborn infant.

\section{Conclusion}

The needs of pregnant incarcerated women involve a complex interconnected web of social, cultural, economic, and political issues. From an ecological systems perspective, changes are needed not only within our communities and the criminal justice system, but also in our belief systems and societal values regarding the treatment of incarcerated women who are carrying an innocent child. Most individuals in the general population have never been incarcerated themselves, let alone incarcerated while pregnant. Therefore, many have never considered the issues and challenges that these pregnant women and their children face. For this reason, awareness of these issues needs to increase amongst the general population.

Even with increased awareness, not everyone will support these women, especially given the fact that they are serving a sentence for crimes they have committed. However, it is important to remember that these women are largely victims of poverty and abuse and have learned to cope with these challenges, not through engaging in violent crimes, but through other maladaptive behaviors. Although beyond the scope of this chapter, these women contend with a host of health and social issues that include the use of illicit drugs, psychological problems, and homelessness, all of which also need to be addressed through effective rehabilitation programs.

Mass incarceration of women, rather than rehabilitation, places an undue burden on families, the often-forgotten victims of the correctional system. Emotionally and physically supporting pregnant incarcerated women begins specifically with pregnancy testing and screening procedures at intake. Early pregnancy identification may be key to improving perinatal health outcomes if facilities subsequently provide proper prenatal and postnatal care. When healthcare services include the provision of proper nutrition, nutrition counseling, opportunities for bonding after birth, and other services to address issues such as drug addiction, jails can play a pivotal role in helping incarcerated women begin to build a better life for themselves and their babies. 


\section{References}

1. Minton TD. Jail inmates at midyear 2011: statistical tables (NCJ-237961). In: Bureau of Justice Statistics Special Report. US Department of Justice. 2011. http://www.bjs.gov/content/pub/pdf/jim11st.pdf . Accessed 30 Jun 2016.

2. Carson EA. Prisoners in 2014 (NCJ-248955). In: Bureau of Justice Statistics Special Report. US Department of Justice. 2015. http://www.bjs.gov/content/pub/pdf/p14.pdf . Accessed 30 Jun 2016.

3. Spjeldnes S, Goodkind S. Gender differences and offender reentry: a review of the literature. J Offender Rehabil. 2009;48:314-35. 10.1080/10509670902850812 .

4. Ferszt GG, Clarke JG. Health care of pregnant women in US state prisons. J Health Care Poor Underserved. 2012;23:557-69. 10.1353/hpu.2012.0048 .

5. Dallaire DH, Forestell CA, Shlafer R. Policy, programs, and interventions regarding pregnant incarcerated women. In: Arditti J, Le Roux T, editors. And justice for all: families and the criminal justice system. Ann Arbor: Michigan; 2015. p. 39-58.

6. Goshin LS, Arditti JA, Dallaire DH, Shlafer RJ, Hollihan A. An international human rights perspective on maternal criminal justice involvement in the United States. Psychol Public Policy Law. 2017;23:53.

7. Carson EA, Sabol WJ. Prisoners in 2011 (NCJ 239808). In: Bureau of Justice Statistics Special Report. US Department of Justice. 2012. http://www.bjs.gov/content/pub/pdf/p11.pdf . Accessed 30 Jun 2016.

8. Committee on Health Care for Underserved Women. Reproductive health care for incarcerated women and adolescent females. Committee opinion no. 535. Obstet Gynecol. 2012;120:425-9.

10.1097/AOG.0b013e318268052d .

9. James DJ, Glaze LE. Mental health problems of prison and jail inmates (NCJ 213600). In: Bureau of Justice Statistics Special Report. US Department of Justice. 2006. http://www.bjs.gov/content/pub/pdf/mhppji.pdf . Accessed 30 Jun 2016.

10. Bloom B, Owen B, Covington S. Women offenders and the gendered effects of public policy. Rev Policy Res. 2004;21:31-48. 10.1111/j.1541-1338.2004.00056.x .

11. Greenfeld LA, Snell TL. Women offenders (NCJ-175688). In: Bureau of Justice Statistics Special Report. US Department of Justice. 1999. http://www.bjs.gov/content/pub/pdf/wo.pdf . Accessed 30 Jun 2016.

12. Fazel S, Bains P, Doll H. Substance abuse and dependence in prisoners: a systematic review. Addiction. 2006;101:181-91. 10.1111/j.1360-0443.2006.01316.x .

13. Grella CE, Lovinger K, Warda US. Relationships among trauma exposure, familial characteristics, and PTSD: a case-control study of women in prison and in the general population. Women Crim Just. 2013;23:63-79. 10.1080/08974454.2013.743376 .

14. Brennan T, Breitenbach M, Dieterich W, Salisbury EJ, Van Voorhis P. Women's pathways to serious and habitual crime: a person-centered analysis incorporating gender responsive factors. Crim Justice Behav. 2012;39:1481-508. 10.1177/0093854812456777 .

15. Salisbury EJ, Van Voorhis P. Gendered pathways: a quantitative investigation of women probationers' paths 
to incarceration. Crim Justice Behav. 2009;36:541-66. 10.1177/0093854809334076 .

16. Tyndall MW, Patrick D, Spittal P, Li K, O'Shaughnessy MV, Schechter MT. Risky sexual behaviours among injection drugs users with high HIV prevalence: implications for STD control. Sex Transm Infect.

2002;78(Suppl 1):i170-5. 10.1136/sti.78.suppl_1.i170 .

17. Clarke JG, Hebert MR, Rosengard C, Rose JS, DaSilva KM, Stein MD. Reproductive health care and family planning needs among incarcerated women. Am J Public Health. 2006;96:834-9.

10.2105/AJPH.2004.060236 .

18. Bell JF, Zimmerman FJ, Cawthon ML, Huebner CE, Ward DH, Schroeder CA. Jail incarceration and birth outcomes. J Urban Health. 2004;81:630-44. 10.1093/jurban/jth146 .

19. Maruschak LM. Medical problems of jail inmates (NCJ-210696). In: Bureau of Justice Statistics Special Report. US Department of Justice. 2006. http://www.bjs.gov/content/pub/pdf/mpji.pdf . Accessed 30 Jun 2016.

20. Cordero L, Hines S, Shibley KA, Landon MB. Duration of incarceration and perinatal outcome. Obstet Gynecol. 1991;78(4):641-5.

21. Martin SL, Rieger RH, Kupper LL, Meyer RE, Qaqish BF. The effect of incarceration during pregnancy on birth outcomes. Public Health Rep. 1997;112:340-6.

22. National Commission on Correctional Health Care. Women's health care in correctional settings. 2014. http://www.ncchc.org/women\%E2\%80\%99s-health-care . Accessed 4 Jun 2016.

23. Timmermans S, Jaddoe VW, Hofman A, Steegers-Theunissen RP, Steegers EA. Periconception folic acid supplementation, fetal growth and the risks of low birth weight and preterm birth: the Generation R Study. Br J Nutr. 2009;102(5):777-85. 10.1017/S0007114509288994 .

24. Peña-Rosas JP, De-Regi LM, Dowswell T, Viteri FE. Daily oral iron supplementation during pregnancy. Cochrane Database Syst Rev. 2012;12:CD004736. 10.1002/14651858.CD004736.pub4 .

25. Collins SA, Thompson SH. What are we feeding our inmates? J Correct Health Care. 2012;18(3):210-8. $10.1177 / 1078345812444875$.

26. Shlafer R. Jail administrators' perspectives of the services and needs of pregnant women incarcerated in county jails. In: 142nd American Public Health Association Annual Meeting and Exposition. Washington, DC: American Public Health Association (APHA); 2014. https://apha.confex.com/apha/142am/webprogram/Paper303178.html . Accessed 30 Jun 2016.

27. Liu J, Raine A. The effect of childhood malnutrition on externalizing behavior. Curr Opin Pediatr. 2006;18:565-70. 10.1097/01.mop.0000245360.13949.91 .

28. Olsen SF, Hansen HS, Secher NJ, Jensen B, Sandström B. Gestation length and birth weight in relation to intake of marine n-3 fatty acids. Br J Nutr. 1995;73:397-404.

29. Freeman M, Hibbeln JR, Wisner KL, Brumbach BH, Watchman M, Gelenberg AJ. Randomized doseranging pilot trial of omega-3 fatty acids for postpartum depression. Acta Psychiatr Scand. 2006;113:31-5. 10.1111/j.1600-0447.2005.00660.x . 
Hypotheses. 2010;74:71-5. 10.1016/j.mehy.2009.07.054 .

31. Institute of Medicine, Food and Nutrition Board. Dietary reference intakes for calcium and vitamin D. Washington: National Academy Press; 2010.

32. Hollis BW, Johnson D, Hulsey TC, Ebeling M, Wagner CL. Vitamin D supplementation during pregnancy: double-blind, randomized clinical trial of safety and effectiveness. J Bone Miner Res. 2011;26:2341-57. 10.1002/jbmr.463 .

33. Forestell CA, Mennella JA. Food, folklore and flavor preference development. In: Lammi-Keefe CJ, Couch SC, Philipson E, editors. Handbook of nutrition and pregnancy. Totowa: Humana Press; 2008. p. 55-64.

34. Godderis R. Dining in: the symbolic power of food in prison. Howard J Crim Just. 2006;45:255-67. 10.1111/j.1468-2311.2006.00420.x .

35. Cate S. "Breaking bread with spread" in a San Francisco County jail. Gastronomica. 2008;8:17-24. http://www.jstor.org/stable/10.1525/gfc.2008.8.3.17?origin=JSTOR-pdf\&seq=1\#page_scan_tab_contents . Accessed 30 Jun 2016.

36. Godfrey KM, Lillycrop KA, Burdge GC, Gluckman PD, Hanson MA. Epigenetic mechanisms and the mismatch concept of the developmental origins of health and disease. Pediatr Res. 2007;61:5R-10R. 10.1203/pdr.0b013e318045bedb .

37. Burdge GC, Slater-Jefferies J, Torrens C, Phillips ES, Hanson MA, Lillycrop KA. Dietary protein restriction of pregnant rats in the $\mathrm{F}_{0}$ generation induces altered methylation of hepatic gene promoters in the adult male offspring in the $F_{1}$ and $F_{2}$ generations. Br J Nutr. 2007;97:435-9. 10.1017/S0007114507352392 .

38. Kelsey CM, Medel N, Mullins C, Dallaire D, Forestell C. An examination of care practices of pregnant women incarcerated in jail facilities in the United States. Matern Child Health J. 2017:1-7. 10.1007/s10995016-2224-5 .

39. Silver HM. Listeriosis during pregnancy. Obstet Gynecol Surv. 1998;53:737-40.

40. Procter SB, Campbell CG. Position of the academy of nutrition and dietetics: nutrition and lifestyle for a healthy pregnancy outcome. J Acad Nutr Diet. 2014;114:1099-103. 10.1016/j.jand.2014.05.005 .

41. Shlafer RJ, Stang J, Dallaire D, Forestell CA, Hellerstedt W. Best practices for nutrition care of pregnant women in prison. J Correct Health Care. 2017;23(3):297-304. 10.1177/1078345817716567 .

42. Dallaire DH, Holmquist Z, Kelsey C. Healthy beginnings in difficult environments: the William \& Mary Healthy Beginnings Project. Healthy Generations Newsletter. Winter 2015.

43. Boyd NR, Windsor RA. A formative evaluation in maternal and child health practice: the partners for life nutrition education program for pregnant women. Matern Child Health J. 2003;7:137-43.

44. Sachdeva R, Mann SK. Impact of nutrition education and medical supervision on pregnancy outcome. Indian Pediatr. 1993;30:1309-14.

45. American Academy of Pediatrics. Breastfeeding and the use of human milk. Pediatrics. 2012;129:e827-41. 10.1542/peds.2011-3552 . 
46. World Health Organization. WHO recommendations on postnatal care of the mother and newborn. Geneva: World Health Organization; 2014. http://apps.who.int/iris/bitstream/10665/97603/1/9789241506649_eng.pdf . Accessed 30 Jun 2016.

47. Mennella JA, Jagnow CP, Beauchamp GK. Prenatal and postnatal flavor learning by human infants. Pediatrics. 2001;107(6):E88. 10.1159/000323397.

48. Galloway AT, Lee Y, Birch LL. Predictors and consequences of food neophobia and pickiness in young girls. J Am Diet Assoc. 2003;103:692-8. 10.1053/jada.2003.50134 .

49. Shim JE, Kim J, Mathai RA, STRONG Kids Research Team. Associations of infant feeding practices and picky eating behaviors of preschool children. J Am Diet Assoc. 2011;111:1363-8. 10.1016/j.jada.2011.06.410 .

50. Else-Quest NM, Hyde JS, Clark R. Breastfeeding, bonding, and the mother-infant relationship. MerrillPalmer Q. 2003;49:495-517. 10.1353/mpq.2003.0020 .

51. Britton C, McCormick FM, Renfrew MJ, Wade A, King SE. Support for breastfeeding mothers (review). Cochrane Database Syst Rev. 2007;1:CD001141. 10.1002/14651858.CD001141.pub3 .

52. Poehlmann J. Incarcerated mothers' contact with children, perceived family relationships, and depressive symptoms. J Fam Psychol. 2005;19(3):350-7. 10.1037/0893-3200.19.3.350 .

53. Wismont JM. The lived pregnancy experience of women in prison. J Midwifery Womens Health. 2000;45:292-300. 10.1186/1471-2393-12-36 .

54. Ystrom E. Breastfeeding cessation and symptoms of anxiety and depression: a longitudinal cohort study. BMC Pregnancy Childbirth. 2012;12:36. 10.1186/1471-2393-12-36 .

55. Ystrom E, Niegel S, Klepp KI, Vollrath ME. The impact of maternal negative affectivity and general selfefficacy on breastfeeding: the Norwegian Mother and Child Cohort Study. J Pediatr. 2008;152:68-72. 10.1016/j.jpeds.2007.06.005 .

56. Libster NR. Breastfeeding initiation among women who have experience with incarceration. College of William \& Mary undergraduate honors theses. Paper 933. 2016. http://publish.wm.edu/honorstheses/933 . Accessed 1 Aug 2016.

57. Dennis CL. Breastfeeding initiation and duration: a 1990-2000 literature review. J Obstet Gynecol Neonatal Nurs. 2002;31:12-32.

58. Corbett KS. Explaining infant feeding style of low-income black women. J Pediatr Nurs. 2000;15:73-81. $10.1053 / \mathrm{jn} .2000 .5445$.

59. Guise JM, Palda V, Westhoff C, Chan BK, Helfand M, Lieu TA. The effectiveness of primary care-based interventions to promote breastfeeding: systematic evidence review and meta-analysis for the US Preventive Services Task Force. Ann Fam Med. 2003;1:70-8. 10.1370/afm.56 .

60. Hannon PR, Willis SK, Bishop-Townsend V, Martinez IM, Scrimshaw SC. African-American and Latina adolescent mothers' infant feeding decisions and breastfeeding practices: a qualitative study. J Adolesc Health. 2000;26:399-407. 10.1016/S1054-139X(99)00076-2 . 
exploratory study. Birth. 2012;39:145-55. 10.1111/j.1523-536X.2012.00528.x .

62. Schafer E, Vogel MK, Viegas S, Hausafus C. Volunteer peer counselors increase breastfeeding duration among rural low-income women. Birth. 1998;25:101-6. 10.1046/j.1523-536x.1998.00101.x .

63. Warner J. Infants in orange: an international model-based approach to prison nurseries. Hastings Women's Law J. 2015;26:65-91.

64. American College of Obstetricians and Gynecologists. Weight gain during pregnancy. Committee opinion no. 548. Obstet Gynecol. 2013;121:210-2.

65. Dallaire DH, Forestell CA, Kelsey C, Ptachick B, McDonnell K. A nutrition-based program for pregnant incarcerated women. J Offender Rehabil. 2017;56:277-94. 10.1080/10509674.2017.1306008 . 